\title{
Clifford D. CONNER, Jean-Paul Marat. Tribune of the
} French Revolution

Londres, Pluto Press, 2012

Michel Biard

\section{(2) OpenEdition Journals}

Édition électronique

URL : https://journals.openedition.org/ahrf/13118

DOI : 10.4000/ahrf.13118

ISSN : 1952-403X

Éditeur :

Armand Colin, Société des études robespierristes

Édition imprimée

Date de publication : 1 mars 2014

Pagination : 236-238

ISBN : 978-2-200-9083-2790-8

ISSN : 0003-4436

Référence électronique

Michel Biard, "Clifford D. conner, Jean-Paul Marat. Tribune of the French Revolution », Annales historiques de la Révolution française [En ligne], 375 | janvier-mars 2014, mis en ligne le 08 juillet 2014, consulté le 05 juillet 2021. URL : http://journals.openedition.org/ahrf/13118; DOI : https://doi.org/10.4000/ahrf. 13118

Ce document a été généré automatiquement le 5 juillet 2021.

Tous droits réservés 


\title{
Clifford D. CONNER, Jean-Paul Marat. Tribune of the French Revolution
}

\author{
Londres, Pluto Press, 2012
}

\author{
Michel Biard
}

\section{RÉFÉRENCE}

Clifford D. CONNER, Jean-Paul MARAT. Tribune of the French Revolution. Londres, Pluto Press, 2012, 178 p., ISBN 978-0-7453-3193-5.

1 Enseignant à la City University of New York, Clifford Conner a publié en 1997 une première biographie de Marat, davantage centrée sur les activités scientifiques de ce dernier. Constatant qu'aucune biographie plus récente n'existe en langue anglaise et que celle de Gottschalk est « out of date ", il entreprend ici de revisiter le chantier, mais avec une attention plus marquée au politique et surtout à la révolution " sociale ». Aux yeux de Conner, non seulement Marat est l'un des protagonistes majeurs de la Révolution, mais il s'inscrit dans une chaîne aujourd'hui toujours représentée par celles et ceux qui luttent pour un monde meilleur («May they triumph, and the sooner the better ", écrit-il dans son introduction - Qu'ils triomphent, le plus tôt sera le mieux). Il achève son ouvrage par ces mots : « Marat would surely be shocked and dismayed to learn that after more than 200 years his struggle for social revolution had lost none of its relevance and urgency. Where is the People's Friend now, when we need him ? " (Marat serait sûrement choqué et consterné de savoir qu'après plus de 200 ans, son combat pour une révolution sociale est toujours aussi nécessaire et urgent. Où est l'Ami $\mathrm{du}$ Peuple maintenant, quand nous avons besoin de lui ?). La dimension militante de l'ouvrage apparaît aussi dans le fait qu'il soit dédié à trois prisonniers de " conscience » américains et publié dans la collection "Revolutionary lives » (les deux autres titres parus sont consacrés, l'un à Leïla Khaled, "icône » de la Résistance palestinienne, l'autre à Winstanley et aux diggers). Les positions citoyennes de l'auteur ainsi affichées, fait-il ici œuvre novatrice? Son travail ne comporte aucune bibliographie, mais ses 
quinze pages de notes laissent apparaître des références classiques (de Gottschalk, Walter ou Massin à Coquard et Goëtz) et nulle source nouvelle. Prenant appui sur les Archives parlementaires, la presse, les écrits de Marat, Conner ne pouvait guère apporter de découvertes importantes, d'autant qu'il ignore certains travaux récents (comme la thèse, pourtant publiée, de Guillaume Mazeau). Dès lors son livre s'apparente à un essai davantage qu'à une étude novatrice. S'il pourra rendre des services à des lecteurs anglo-saxons, il ne peut en aucun cas se substituer à la bibliographie en français (ce qui n'entrait de toutes façons en rien dans ses intentions).

2 Scindé en cinq chapitres rythmés par un cheminement chronologique, il évoque successivement les premières années de la vie de Marat, puis l'homme de sciences entre 1765 et la Révolution ; enfin, les trois quarts du livre sont, en bonne logique, consacrés aux années 1789-1793 (avec deux ruptures : Varennes et la fusillade du Champ-de-Mars, d'un côté, les massacres de septembre 1792 et l'élection de la Convention nationale, de l'autre). Après une introduction qui revisite les idées reçues (Marat était-il un charlatan, un fou, un criminel... ?), pour bien sûr les anéantir, Conner suit fidèlement le trajet de l'Ami du Peuple et le lecteur pourra retrouver au fil de son récit les événements marquants de la Révolution (14 juillet, 4 août, journées d'octobre) et les premières attaques lancées par les autorités contre l'homme de plume à la rhétorique enflammée. Selon Conner, la répression contre la mutinerie de Nancy à l'été 1790, avec le sinistre sort réservé aux soldats suisses du régiment de Châteauvieux, forge la réputation d'un Marat prompt à deviner les complots et à mettre en garde les citoyens. Même si « le prophète Marat » (Hébert) ou «Cassandre Marat » (Desmoulins) se trompe beaucoup plus souvent dans ses prédictions qu'il ne parvient à annoncer les réalités à venir, il se transforme de fait en protagoniste de tout premier plan. Son engagement en faveur d'une égalité sociale, son hostilité aux autorités constituées, son aptitude à «nager à contre-courant » et à ne pas craindre d'être isolé, son refus de plier devant la répression, sa capacité à s'attirer des soutiens et à utiliser tout un réseau pour faire entendre la voix de l'Ami du Peuple... tout cela atteste l'exemplarité de son engagement aux yeux de son biographe. Et les années 1792-1793 ne démentent point cet engagement. Pour autant, quand bien même la sympathie du lecteur serait acquise à la démonstration et/ou au personnage, peut-on passer sous silence un certain nombre d'approximations et erreurs : écrire que la monarchie aurait " perdu toute crédibilité " et que ses jours seraient " comptés " à l'été 1791 relève de la téléologie car à chaud le constat est fort différent; les vingt-quatre représentants du peuple élus à Paris seraient montagnards et auraient l'appui de cinquante à soixante autres membres de la Convention (!) ; la Plaine regrouperait $70 \%$ des représentants du peuple (!!); vingt et un Girondins auraient été guillotinés le 30 octobre 1793 (rappelons que Valazé s'est suicidé le 30 et que l'exécution des autres a lieu le lendemain); etc. Enfin, parfois certains passages laissent le lecteur sur sa faim, ainsi à propos des massacres de Septembre. Si responsabilité de Marat il y a eu, ce n'est pas par le rôle qu'il occupait alors, mais par la radicalité des propos tenus dans son journal depuis longtemps déjà. Reste un dernier point. Est-ce bien utile de se demander ce qu'il serait advenu de Marat s'il n'avait été assassiné, a fortiori pour imaginer qu'il aurait sans doute été guillotiné aux côtés de Hébert? Outre le fait que l'hypothèse n'a guère de sens, il me semble plus que jamais important de souligner que nombre de différences séparaient l'Ami du Peuple et le Père Duchesne, tout comme il faut une fois de plus rappeler qu'on rapproche trop souvent de façon simpliste les Enragés et les « Hébertistes » (quand ils ne sont pas purement et simplement confondus par certains historiens). Évoquer la 
radicalité de leurs positions ne peut suffire à les amalgamer, sauf à vouloir démontrer qu'une même volonté de révolution "sociale " les unissait et que cette volonté reste d'actualité 220 ans plus tard. En soi, pourquoi pas et chaque citoyen/ne en jugera comme il/elle l'entend, pour autant l'Histoire n'aura pas fait là un pas de géant. 